\title{
LAS RELACIONES
}

DEL CRISTIANISMO

Y EL GOBIERNO

IMPERIAL ROMANO

EN LOS TIEMPOS DE

AGUSTÍN DE HIPONA

Roberto Jaramillo Escutia*

RESUMEN: En este artículo se pretende clarificar el desarrollo de las relaciones entre el Imperio romano y la Iglesia católica durante la vida de san Agustín (354-430). Se pone especial énfasis en las motivaciones político-religiosas de los emperadores romanos de esa época, así como en el aspecto político-social de algunas controversias doctrinales en el seno del cristianismo (herejías).

\author{
yod \\ THE RELATIONSHIP BETWEEN CHRISTIANITY \\ AND THE GOVERNMENT OF THE ROMAN EMPIRE DURING \\ THE YEARS OF AUGUSTINE OF HIPPO
}

ABSTRACT: In this article, we will attempt to shed light on the relationship between the Roman Empire and the Catholic Church during Saint Augustine's life (354-430). We will focus on the politico-religious motivations of the Roman emperors during this period as well as the socio-political aspects of various doctrinal controversies in Christianity (heresy).

PALABRAS CLAVE: emperadores romanos, relaciones Iglesia-Estado, cesaropapismo.

KEY WORDS: Roman emperors, Church-State relationship, Caesaropapism.

RECEPCIÓN: 7 de noviembre de 2016.

APROBACIÓN: 14 de febrero de 2017.

*Universidad Pontificia de México. 
CITAM Derechos Reservados.

La reproducción total o parcial de este artículo se podrá hacer si el ITAM otorga la autorización previamente por escrito. 


\title{
LAS RELACIONES \\ DEL CRISTIANISMO \\ Y EL GOBIERNO \\ IMPERIAL ROMANO \\ EN LOS TIEMPOS DE \\ AGUSTÍN DE HIPONA
}

\begin{abstract}
Agustín de Hipona vivió del 13 de noviembre de 354 al 28 de agosto de 430 . Recientemente, hace menos de diez años, su persona fue escogida para proponer cinematográficamente la debacle del Imperio romano de Occidente, y me parece que también es un ejemplar único para iluminar esas relaciones iniciales, que todavía en su tiempo no podemos llamar Iglesia-Estado, pues no se puede hablar de un ente denominado Iglesia cristiana como de algo homogéneo, que actuara al compás de unos mismos acuerdos, o algo por el estilo.
\end{abstract}

\section{Antecedentes}

Para situarnos convenientemente en esas relaciones del Estado imperial romano y el cristianismo, antes del nacimiento de este, debemos tener claro que en las instituciones imperiales nada podía ser concebido fuera del Estado y menos en su contra. La religión grecolatina era una función del Estado; por lo mismo, se trataba de una simbiosis perfecta, en la que la autoridad civil fungía a la vez como sacerdote del culto tradicional. En consecuencia, era impensable que pudiera surgir un problema de libertad religiosa. Como la religión era considerada una institución pública, perteneciente al patrimonio político de la comu- 
nidad, no del individuo, ningún ciudadano habría podido adoptar su propia religión, en contraste con la de la respublica; luego, no debía existir diferencia alguna entre el ciudadano y el fiel participante del rito dedicado a los númenes (es más, para ser ciudadano se debía venerar a la misma divinidad).

Por otra parte, conforme se fueron uniendo al Imperio diferentes pueblos, con distintas divinidades nacionales, estas fueron consideradas óptimas para esos pueblos, y los romanos no dudaron en acogerlas erigiéndoles su respectivo templo en la capital, el Pantheon. No estaban muy seguros de venerar a todos los númenes del universo, pero tampoco podían prohibir divinidades particulares, para no ofenderlos ni crear conflictos que podrían ser muy perjudiciales para la paz del Imperio. Por esto, como factor de unidad religiosa y símbolo de unión con la nueva entidad política, se sobrepuso el culto imperial, como signo de fidelidad, y así se respetaban plenamente los principios religiosos de los pueblos. En cambio, los cristianos no podían invocar ninguna benevolencia, pues su divinidad no era la de un pueblo y además era exclusivista, al grado de no compartir con otras divinidades ningún signo de culto exterior.

En este contexto, las órdenes imperiales exigían a los ciudadanos cumplir con determinados ritos a los dioses, que los cristianos no acataban, por lo cual llegaban a ser ajusticiados. Las órdenes no tenían la intención de prohibir esa religión ni de perseguirlos sádicamente, sino que les pedían que manifestaran con los signos debidos, esos sí ritos culturales, su fidelidad como ciudadanos al Imperio. Es decir, no había separación entre lo civil y lo religioso, sino que más bien se provocaba una confusión; lo civil se manifestaba con signos religiosos, y estos convertían al participante en ciudadano, cives. Así, podemos afirmar que cuando se concedió licitud al cristianismo, se inició una incipiente división entre lo civil y lo religioso, que como vamos a ver duró poco tiempo.

El cristianismo pasó de ser una religión ilícita a convertirse en la religión preferida del emperador Constantino. Este paso tan radical era impensable, pues cuando más se aspiraba a un modus vivendi, una simple tolerancia; tanto, que este giro radical provocó muchas veces, en ambas partes, que no se pudiera establecer un punto justo de equilibrio. Más, 
si tenemos en cuenta que se calcula que a comienzos del siglo IV solo una décima parte de los habitantes del Imperio eran cristianos.

Se había llegado a esta situación por obra de dos documentos: el Edicto de Sárdica y el Acuerdo de Milán; pero tuvo mayor importancia la actitud benevolente de Constantino, aunque no se haya bautizado hasta encontrarse en el lecho de muerte. El Edicto de Sárdica, dado por el emperador Galerio el 30 de abril de 311, reconoció al cristianismo como religión lícita, pero no le devolvió los bienes que los edictos de Diocleciano le habían confiscado. Este documento es importante para nuestro tema, pues afirma que la finalidad de las persecuciones es conducir a los cristianos a las leyes y costumbres de sus antepasados y a lo que llama publicam disciplinam romanorum, es decir, a que se comporten como ciudadanos. Esta licitud del cristianismo inició cierta separación entre el gobierno imperial y una religión que no era la oficial ni la de algún pueblo incorporado al imperio.

El Acuerdo de Milán se atribuye normalmente a Constantino, pero hay que aclarar el hecho histórico: no es edicto, ni lo dictó Constantino ni se promulgó en Milán; se trata de un rescripto enviado por el emperador Licinio al gobernador de Bitinia, tras haber quedado como único gobernante de Oriente, el 13 de junio de 313. Ciertamente, se trata de un documento pactado en Milán entre Constantino y Licinio, cuando este último iba a contraer nupcias con la hermana del primero, Constancia. En él se proclama el principio de libertad religiosa, con referencia especial a los cristianos, y se les restituyen los lugares de culto y los bienes inmuebles confiscados durante la persecución.

\section{La época constantiniana (312-337)}

Como se indicó, lo más importante para el desarrollo del cristianismo fue la actitud imperial. Su acercamiento a esta religión se inició en los días previos a la batalla de Puente Milvio, el 30 de abril de 312, en la que Constantino derrotó a Majencio y conquistó Roma, y atribuyó la victoria al dios de los cristianos. Fue una adhesión al cristianismo imperfecta y por motivos no del todo sublimes, sino más bien mágicos, pero sinceros. 
Constantino llevó adelante una nueva política filocristiana, así que se puede hablar de época constantiniana, aunque su bautismo haya ocurrido el 22 de mayo de 337, día de su fallecimiento.

Único emperador desde el 324, en el régimen de Constantino se puede valorar con bastante claridad, por una parte, su actitud hacia la religión oficial, con la que no rompió totalmente, pues conservó el título de Pontifex Maximus, pero tomó algunas medidas que limitaron su influencia; por ejemplo, despojó a los templos de sus riquezas. En cambio, al cristianismo lo colmó de favores: concedió a los obispos jurisdicción en causas civiles, estableció como día de reposo semanal el dies solis, para facilitar a los cristianos su participación en el culto (3 de julio de 321); mandó construir basílicas con gran munificencia: San Pedro, San Paulo y San Lorenzo en Roma, Santo Sepulcro en Jerusalén, la de Belén, la Aurea de Antioquía, etc. Además, comenzó la injerencia del gobierno estatal en los asuntos internos de la Iglesia, lo que se puede comprender, porque muchas veces Constantino intervino tras haber sido interpelado por los obispos, sobre todo los cortesanos. Razonaba, quizás, que si solicitaban su juicio no solo era lícito, sino obligatorio tomar una decisión en consecuencia. De hecho — según Eusebio de Cesarea-, se consideraba episkopos ton ektós, obispo para quienes estaban fuera del cristianismo, aunque como esta frase la pronunció en la inauguración del Concilio de Nicea, más coherente sería una interpretación que lo colocara como supremo moderador de tal asamblea.

Hasta aquí hemos tocado los antecedentes civiles; ahora entramos en los eclesiásticos. El problema más arduo fue el arrianismo, y en las controversias que suscitó Constantino tomó las primeras decisiones gubernamentales en el campo religioso. Según Arrio, Dios no siempre había sido Padre, pues el Verbo fue creado de la nada, pero no desde un principio, por lo que el Hijo era una criatura, no era igual al Padre en cuanto a la substancia y fue hecho solo para que por su medio Dios nos creara; de lo contrario, no hubiera existido jamás. Esta doctrina fue condenada en Alejandría en 321. Arrio se refugió en Cesarea de Palestina, donde con el apoyo del obispo Eusebio, padre de la historia eclesiástica, difundió por todo el Oriente su doctrina. 
El emperador Constantino, viendo que peligraba la paz religiosa, envió a Alejandría a su consejero eclesiástico, el obispo de Córdoba Osio, quien no logró la paz pero se dio cuenta de la importancia del asunto, por lo que recomendó la celebración de un concilio. Constantino aceptó, y así se verificó el primer concilio ecuménico, el Concilio de Nicea, inaugurado por el propio emperador el 20 de mayo de 325. Ahí se afirmó, en contra de Arrio, la consustancialidad del Padre con el Hijo, usando por primera vez un término no bíblico, Homoousios to Patri, susceptible de interpretación errónea y que por ello topó con grandes dificultades para su aceptación.

Como Constantino había decidido que quienes no firmaran las actas conciliares serían exiliados, y efectivamente lo cumplió, incluso con quienes más tarde se arrepintieron, los partidarios de Arrio optaron por no atacar el concilio, sino a los defensores de Nicea, y así la controversia se eternizó, ya que en Oriente se sentían más convencidos de la doctrina de Arrio.

En cuanto al cisma africano, el donatismo, que de ser un movimiento estrictamente religioso se transformó en uno político y social, había surgido con el primer decreto de persecución de Diocleciano, que ordenaba consignar los libros sagrados para quemarlos. Muchos obedecieron el edicto. Aquí debo subrayar que en el cristianismo nunca se han considerado sagrados los libros, pero entonces pareció una especie de traición, y para tapar esa falla, se acuñó una doctrina según la cual solo son miembros de la Iglesia los santos, por lo que la santidad de la Iglesia depende de la santidad de sus miembros y la validez de los sacramentos depende de la santidad o dignidad del ministro. Ya en tiempos de paz, se produjo una duplicidad de obispos en Cartago. Se adujo que uno de los obispos que consagraron a Ceciliano había consignado libros y, por lo tanto, era inválida su consagración. El nombre proviene de Donato, apodado el Grande, que desde 313 dirigió a los cismáticos.

Los del bando de Ceciliano acudieron a Constantino solicitando un juicio imparcial de los obispos de la Galia, que no habían sufrido la persecución. No acataron la primera evaluación dada en un sínodo romano, apelaron nuevamente $y$, antes de darles otra oportunidad, Constantino mandó hacer una investigación judicial basada en las actas de consig- 
nación, que resultó negativa para el acusado. Se reunió una nueva asamblea en Arlés en agosto de 314, en la que de nueva cuenta resultaron condenados los donatistas, que ya estaban rebautizando a sus fieles.

Dado que Constantino le daba gran importancia al orden público, tuvo una actuación vacilante. No aplicó la decisión de Arlés, sino que envió dos comisarios a África para que emprendieran una nueva investigación en el verano de 316 . Los comisarios confirmaron que Ceciliano era el obispo legítimo. Los cismáticos se entregaron a actos de violencia, lo que obligó a Constantino a publicar una ley el 10 de noviembre de 316, por la que debía restablecerse por la fuerza la unidad religiosa en África. La ley fue aplicada con rigor por la tropa, y hubo muertos y heridos, con lo que los cismáticos tuvieron a sus propios mártires, signo de veracidad para su iglesia.

Esto es importante, porque a partir de entonces se formó un grupo religioso particular que cuidaba del culto martirial, los circumceliones, fanáticos que se convirtieron en terroristas muy temidos, pues la muerte no les importaba, sino que la aceptaban como martirio. En este primer periodo de proscripción, el donatismo se convirtió en un movimiento complejo, que aprovechó el descontento de las clases desheredadas africanas para transformarse en una opción política contra el Estado, de modo que proclamó, por primera vez, la separación entre el cristianismo y el gobierno imperial. Cuando Constantino se preparaba para atacar a Licinio, aceptó el 5 de mayo de 321 una solicitud de tolerancia para los donatistas. En adelante, el emperador mostró una actitud benévola, con lo que el movimiento se difundió extraordinariamente.

\section{Los hijos de Constantino (337-361)}

Constantino, al crear una dinastía absoluta, parece que pensó en el mayor de sus hijos con Fausta, Constantino II, como sucesor, aunque otros suponen que proyectó un colegio de augustos jerarquizado, una tetrarquía familiar. Como no dejó nada establecido, sus hijos hicieron una masacre de todos los miembros varones de la familia, de la que únicamente se salvaron, por su corta edad, su sobrino Galo y su hermano 
Juliano. A partir de ese momento, el poder quedó dividido en dos. De un lado, la mentalidad imperial en Oriente y del otro en Occidente, incluso cuando se trate de la misma persona.

E1 9 de septiembre de 337, sus hijos sobrevivientes fueron declarados augustos por el Senado y se dividieron el Imperio, dejando con la peor parte al supuesto heredero, Constantino II, pero como el menor, Constante, sospechó que su hermano quería quitarle su territorio, se alió con Constancio II, y lo liquidaron en 340. Constante se quedó con el Imperio de Occidente hasta su muerte, asesinado, diez años después, el 18 de enero de 350. Constancio II fue el señor de Oriente y único emperador desde 351, cuando venció al asesino de su hermano, Magnesio, en Mursa.

Durante el gobierno de estos hermanos se dieron varios decretos de prohibición del culto grecolatino y cerraron templos, lo que se debió atemperar, pues las festividades de los númenes eran el origen de los juegos de los pueblos, y no era aconsejable la terminante desaparición de los lugares de culto. Estas medidas provocaron la destrucción de joyas del arte universal.

En cuanto al donatismo se refiere, con Constante como único emperador de Occidente hubo un nuevo intento de unidad, por medio del diálogo con los cismáticos, y se ofrecieron dones a las comunidades, lo que enojó tremendamente a Donato. Ante las protestas de Donato, Constante renovó el edicto de unión de su padre del 15 de agosto de 347, disolvió las comunidades cismáticas y exilió a quienes se opusieron, entre ellos el propio Donato. Otra vez hubo violencia y mártires donatistas, y esta situación se extendió hasta el ascenso de Juliano al trono.

Tornemos al arrianismo, que con los hijos de Constantino alcanzó su apogeo, precisamente con el apoyo imperial. La razón parece estar en que tratándose de un problema oriental, fue en esa región donde la decisión de Nicea tuvo más detractores, y por lo tanto, a los emperadores que gobernaron esa parte del imperio les parecía que para lograr una paz religiosa, tendrían que apoyar al bando contrario. Así, por un lado, Constante se preocupó por restablecer el diálogo entre las iglesias de Occidente y Oriente, hasta lograr que se condenara el arrianismo puro 
y se moderara la actitud de su hermano Constancio II, pero una vez que este quedó como único gobernante, influido por los más radicales apoyó firmemente a la facción antinicena y trató de expandir un semiarrianismo por todo el imperio. Tan fuertes se sintieron los antinicenos por el apoyo imperial, que se dividieron en sectas enfrentadas por un antagonismo feroz. Se exiliaron unos a otros y causaron una verdadera confusión episcopal, por existir muchos obispos sin sede.

Constancio II, una vez que se desembarazó del usurpador Magnesio, comenzó a extender su plan en Occidente, y para atemorizar a los obispos, cuando estos se negaban a cumplir sus mandatos, pronunció frases como esta: Et quod ego volo, id pro canone habeatur, y lo que yo quiero se tenga por mandato. Ya desde el mismo Concilio de Milán de 355, donde pronunció tales palabras, los mismos obispos le respondieron que no tratándose de asuntos temporales, sino religiosos, no podía juzgar su conveniencia, aunque después los convenció uno tras otro. Quien resistió siempre fue el casi centenario consejero religioso de su padre, Osio de Córdoba, que respondió duramente a una carta personal de Constancio II, diciéndole que no le era lícito ni tenía poder para ejercer funciones de sacerdote, así como los obispos no mandaban en las cosas terrenas. Constancio II, no obstante la edad de Osio, lo exilió.

En buena medida, se debe achacar esta actitud a los obispos palaciegos que se valían del poder de Constancio II y lo adulaban llamándolo episcopus episcoporum, "obispo de los obispos". Con este mutuo apoyo el emperador legisló en cuestiones dogmáticas y se erigió en el primer cesaropapista por sistema. Quería restituir la paz y la unidad religiosa, pero él era el primer impedimento, pues con su injerencia provocó grandes desórdenes. Constancio II enfermó gravemente de improviso y falleció el 6 de noviembre de 361, bautizado, como su padre, en el lecho de muerte. Siete años antes había nacido Agustín en Tagaste de Numidia.

\section{Juliano el Apóstata (361-363)}

Asumió el gobierno del Imperio Juliano, sobrino de Constancio II, que en ese momento se encontraba en marcha hacia Constantinopla para atacar a su tío. Constancio II le había encomendado el gobierno de las 
Galias, pero a finales de 359, le solicitó algunas legiones para la guerra contra los Persas. Las tropas se amotinaron y proclamaron Augusto a Juliano. Como Constancio II no lo aceptó, bajaba en son de guerra cuando en Naissus se sometió en febrero de 361 al taurobolio, abrazó como dios personal al sol y ofreció sacrificios a los dioses. Juliano llegó a Constantinopla el 11 de diciembre, le organizó a su tío unos solemnes funerales y decretó su apoteosis, aunque lo sepultó en la Basílica de los Santos Apóstoles. Su reinado fue corto, pues murió el 26 de junio de 363, y aunque aparentemente se dedicó a preparar la lucha contra los persas, se dio tiempo para muchas cosas más.

Juliano fue un hombre de grandes cualidades. Pagano convencido, místico, dedicó su gobierno a la obra para la cual pensaba los dioses lo habían elegido, es decir, a restaurar su culto. Ingenuamente, como iluminado, creyó que podría transmitir su íntima espiritualidad, por la cual daba más importancia a los principios de la caridad, al perfeccionamiento ascético y a una teología espiritual, que a la consecución de bienes y cargos materiales. Sumamente religioso, estimaba más el título de Pontifex Maximus que el de Augustus, por lo que de inmediato hizo construir en Constantinopla un gran templo a Mitra. Se trataba de una vuelta a la amalgamación del poder político con la religión.

Antes de terminar 361 ya había promulgado varios edictos para restaurar el culto a los dioses, reabrir sus templos, restituirles todos sus objetos, incluidos mármoles o columnas empleados en otros edificios (debían restaurarlos o reedificarlos quienes los habían destruido). Pretendió una renovación del helenismo, como él lo llamaba, inspirándose en el cristianismo: a) Organizó la jerarquía: En el vértice él, Pontifex Maximus, en cada provincia un pontífice, en cada ciudad un archisacerdote, todos nombrados por él, que cuidaría llevaran una vida ejemplar. b) Culto: descendía a los mínimos detalles, himnos, cantos, música. Quería una especie de homilía en la que se explicaran los dogmas helénicos. c) Se propuso imitar la caridad de los cristianos, pues mientras que ningún judio pide limosna, mientras los impíos galileos nutren a sus pobres, es una vergüenza que los nuestros estén desprovistos de toda ayuda de nuestra parte. Como se puede apreciar, en esta renovación lo único antiguo es el culto a los dioses, el resto son cosas nuevas. 
Por otra parte, desde sus primeros edictos concedió la tolerancia religiosa para todos los cultos y todas las tendencias, aun para los galileos. Llamó del exilio a todos los obispos desterrados y devolvió la vida a la iglesia donatista en África, con la intención de fomentar las divisiones internas entre los cristianos. Además, revocó los privilegios otorgados a los cristianos por Constantino y combatió el culto martirial poniéndolo en ridículo.

Pero su plan era más ambicioso. El 17 de junio de 362 promulgó su ley escolástica, la más pérfida de todas por su aparente inocuidad. Según la ley, era necesario que los maestros estuvieran de acuerdo con las ideas de los autores que utilizaban; para ello, otorgaba al Senado el derecho de elegir a los maestros, considerando sobre todo su moralidad, la cual se entendía como la coherencia del maestro, pues pensar de un modo y enseñar de otro denotaba falta de sinceridad y honestidad y era un verdadero engaño a los alumnos. La idea era reorientar a las nuevas generaciones hacia el culto a los dioses, excluyendo de la enseñanza a los maestros cristianos y considerando las escuelas como seminarios del paganismo. Se trataba también de cerrar el camino al cursus honorum, la administración estatal, a los jóvenes cristianos que se negaran a ser instruidos por maestros paganos, ya que los maestros cristianos todavía enseñaban con los textos de los clásicos.

Todas estas medidas se basaban en la íntima convicción de Juliano de que el cristianismo había echado a perder la gran civilización helénica, como trata de probar en su obra Contra galileos, que no sobrevivió a la hoguera y de la cual solo se conservan fragmentos trasmitidos por la refutación de Cirilo de Alejandría. Para Juliano, el cristianismo, o la conjuración de los galileos, era un conjunto de fábulas y de irracionalidades inventadas por malvados, y una enfermedad de la inteligencia, derivada de la falta de cultura. Como buen conocedor del dogma cristiano, comenzó su demolición desde el Antiguo Testamento. Puso de relieve las cuestiones ilógicas, como la soberbia judía de considerarse el único pueblo elegido por Dios, cuando hubo otras civilizaciones muy superiores. Negó la divinidad de Cristo, porque los evangelistas le aplicaron arbitrariamente los textos del Antiguo Testamento; en consecuencia, 
negó también la resurrección. Odiaba especialmente a San Pablo, por ser el responsable de la conversión de los griegos, que él consideraba una forma de corrupción, y poco menos a San Juan, por haber sido el causante de proclamar la divinidad de Cristo. Se burlaba especialmente de los monjes, incitados por los demonios a odiar y apartarse del género humano, pues el hombre es un animal social. En pocas palabras, la doctrina de Cristo no era útil a la humanidad.

Muchos cristianos que se habían convertido por conveniencia, regresaron al politeísmo; sin embargo, este hiato en la cristianización del imperio más bien ayudó al cristianismo, pues cuando los obispos analizaron lo que podía ocurrir, se unieron frente al peligro y comenzaron a restablecer la unidad amenazada por el arrianismo.

Con la muerte de Juliano se extinguió la línea masculina de la familia constantiniana. Juliano no quiso designar un sucesor, con lo que pasó nuevamente la elección al ejército, que en el mismo campo de batalla aclamó a Joviniano, pero este falleció pronto, el 17 de febrero de 364.

\section{Los valentinianos y Teodosio (364-395)}

Nuevamente la tropa entregó el trono a Valentiniano I, quien asoció a su hermano Valente como segundo Augusto. Valentiniano gobernó la parte occidental y Valente la oriental. Ellos fueron los que dividieron al Imperio, funcionarios, ejército, economía, agricultura, todo. Cada Augusto se vio limitado por sus medios y trazó sus propios objetivos, encerrado en su territorio y prisionero de su egoísmo, que creció con los problemas.

En Occidente, Valentiniano I, aunque profesaba el nicenismo, en las cuestiones religiosas actuaba siguiendo el principio de neutralidad, al grado de que no le gustaba escuchar que alguien fuera cristiano por ser la religión del emperador. Así, no solo por motivos políticos, sino también porque pensaba que como laico no debía inmiscuirse en cuestiones de fe, incluso fue objeto de quejas de obispos que querían que tuviera mayor injerencia. Falleció en 375. Valente, en cambio, como en Oriente el nicenismo no era la corriente central, persiguió a sus fieles, así como también a seguidores de las corrientes menos extremistas del 
arrianismo, y los trató con métodos bárbaros. Desterró y hasta ejecutó a quienes se negaban a apoyarlo en su pretensión de unificar su Imperio bajo la corriente más radical, el omeísmo. Falleció el 9 de agosto de 378 .

La disolución del arrianismo comenzó en Occidente, con el Sínodo de París de 361, cuando las tropas de Juliano avanzaban sobre Constantinopla. También se aprovechó la libertad concedida por Constantino. Incluso el símbolo del nicenismo, Atanasio, celebró su sínodo en Alejandría. En Occidente, le imprimió mayor celeridad la elección como obispo de Milán del consularis Ambrosio, entonces catecúmeno y que se había presentado con la fuerza pública para calmar los tumultos causados por la muerte del obispo arriano Ausencio. Bautizado al poco tiempo, Ambrosio fue consagrado obispo una semana después, en 374. La importancia de este hecho se cifra en que el obispo influyó grandemente en el siguiente emperador, Graciano, y con su apoyo se puso fin al arrianismo en Occidente.

El régimen de Graciano se extendió de 375 a 383, y aunque el ejército le había asociado a su hermano menor Valentiniano II, gobernó en solitario en Occidente y por un breve periodo también en Oriente, de agosto de 378 a enero de 379, cuando designó emperador a Teodosio.

82 Con Graciano, fuertemente influido por Ambrosio, se radicalizó la separación entre el poder político y el culto grecolatino, al suprimir de entre los títulos imperiales el de Pontifex Maximus. Luego, en 382, promulgó dos constituciones por las que retiró a los sacerdotes del culto oficial sus exenciones e inmunidades, suspendió todo subsidio estatal para su culto y confiscó templos y colegios sacerdotales. Graciano ordenó también remover del aula del Senado el altar de la Victoria, donde los senadores juraban, lo que tuvo un gran significado religioso y político. Con estas decisiones, prácticamente condenaba a muerte la religión grecolatina, al quitarle el sostén económico que la sustentaba y separarla del poder imperial, el cual, en cambio, acercó al cristianismo, pues poco antes, en 380, proscribió toda herejía cristiana en el imperio. Ambrosio aprovechó esta orden para limpiar de arrianos Occidente. Ambrosio fue el que prescribió la asistencia del brazo secular para ejecutar las sentencias eclesiásticas sobre los clérigos contumaces. 
Teodosio, primero como emperador de Oriente en 379, y a la muerte de Valentiniano II, en 392, de Occidente, fue el único poder hasta su muerte ocurrida el 17 de enero de 395. Teodosio optó por la unidad religiosa del imperio como política de Estado, como el mejor medio para alcanzar la unidad política. Por esto atacó no solo el culto grecolatino, sino que también persiguió a los herejes; por esta doble razón, proclamó al cristianismo niceno religión oficial del Imperio romano, con lo que dio por terminada la libertad de religión, con el Edictum de Fide Catholica, publicado en Tesalónica el 28 de febrero de 380. En el edicto se establecía que todos los habitantes del imperio debían profesar la religión enseñada por el apóstol Pedro a los romanos y que profesaban Dámaso de Roma y Pedro de Alejandría: Hic est Patris et Filii et Spiritus Sancti, unam Deitatem sub parili maiestati et sub pia Trinitate credamus, "Creamos que el Padre, el Hijo y el Espíritu Santo son un solo Dios, con igual majestad, y bajo una santa Trinidad". Con este edicto les quitó a los herejes arrianos toda opción a la existencia, aunque tuvo que reformarlo en enero de 381, por sus pactos con las tropas de los pueblos godos, que eran arrianos, para permitirles conservar sus iglesias, aunque fuera de las ciudades, donde acampaban las tropas. Además, para que esta determinación no quedara en el aire, en noviembre de 379, Teodosio invitó al obispo arriano de Constantinopla Demófilo a abrazar la fe nicena. Como este se negó, le ordenó entregar todas las basílicas, y el día 27 acompañó a Gregorio Nacianceno, que por entonces presidía a los nicenos, a la Basílica de los Santos Apóstoles, y de propia voz lo nombró obispo de la ciudad. Más tarde, el sínodo episcopal declaró canónica esta imposición. Este gesto tuvo grandes repercusiones para la cristiandad oriental, pues a partir de ese momento la corte cumplió un papel de primer orden en la designación del obispo capitalino, incluso ya en época otomana.

Para confirmar su programa religioso, Teodosio convocó un concilio en Constantinopla en mayo de 381, que con el tiempo fue reconocido como el segundo concilio ecuménico, por el contenido de su temática. Lo inauguró, pero después no intervino. Aunque se pretendía que fuera de unidad, los de tendencia arriana abandonaron la sede conciliar antes del inicio, negándose a integrarse en el nicenismo. Lo más 
importante del concilio fue su símbolo de fe, que desde entonces será el credo de todos los cristianos hasta la fecha y la causa principal de la ecumenicidad del concilio. Confirmó el símbolo niceno, completándolo en lo relativo a la consubstancialidad y divinidad del Espíritu Santo.

Teodosio ratificó todas las decisiones conciliares con un edicto del 30 de julio de 381, en el que además proscribió a los herejes, los cuales debían entregar sus iglesias; es decir, convirtió en ley del Estado los decretos del concilio. De esta manera se desvaneció el arrianismo en el Imperio romano, pero permaneció entre los germanos y regresó en el siglo siguiente. De igual forma, el Estado se ató al cristianismo.

No terminaron con esto los empeños de Teodosio. También se lanzó contra paganos y apóstatas en varias constituciones entre 381 y 383 . Después se empeñó en facilitar el restablecimiento de la paz entre los cristianos y trató de llegar a una unanimidad doctrinal. Con una serie de edictos promulgados entre el 25 de julio de 383 y el 21 de enero de 384 reconoció únicamente el nicenismo, quitó a los herejes sus lugares de culto y privó a los apóstatas de todo derecho civil y político en 391. A los que permanecieron fieles a los dioses latinos les prohibió el 25 de mayo de 385 el ejercicio de su religión, de modo que no pudieron ofrecer sacrificios ni celebrar otras ceremonias públicas, y el 24 de febrero de 391 prohibió toda ceremonia en Roma, una prohibición que se extendió luego a Egipto. No todas estas órdenes se ejecutaron, pero algún peso tuvieron.

La Iglesia cristiana se volvió dependiente del poder imperial. Lo provocaron los mismos obispos, que continuamente recurrían a la autoridad de los emperadores para hacer valer sus puntos de vista doctrinales, con lo que se sintieron árbitros de estas cuestiones eclesiásticas. Peor aún, estas decisiones adquirieron carácter civil y, por lo tanto, se borraron los límites entre lo estatal y lo religioso, y se confundió la sociedad.

De mayor interés para nosotros es que el emperador Teodosio fue el único gobernante que oficialmente debió hacer penitencia pública para ser reconciliado por el obispo Ambrosio, la noche de Navidad de 390, tras un incidente sucedido en Tesalónica, que luego se conoció como la masacre de Tesalónica. El magister militum del pretorio de 
la ciudad, el godo Buterico, mandó arrestar a un popular auriga por haber tratado de seducir a un sirviente del emperador e incluso a él mismo. El pretorio quiso aplicar una ley contra la homosexualidad promulgada por Teodosio ese mismo año. El populacho, amotinándose, exigió la liberación del auriga, a lo que se negó Buterico, que resultó muerto en el tumulto que se sucedió. Teodosio ordenó que se tomaran represalias, de las que al parecer una contraorden no alcanzó a llegar. Las tropas enardecidas de Buterico vengaron a su jefe en el circo, donde causaron un gran número de víctimas, que algunos calculan en siete mil. Por esto, Ambrosio invitó en una carta a Teodosio a hacer penitencia, lo que aceptó, dado que como afirmaba el obispo, el emperador cristiano era parte de la Iglesia y no estaba por encima de sus normas, Imperator enim intra Ecclesiam, non supra Ecclesiam est. No se trata, como algunos autores piensan, de la humillación del poder político frente al eclesiástico, sino del arrepentimiento de un cristiano tras reconocer un pecado público, que era lo único por lo que entonces se obligaba una penitencia pública. Así, en su oración fúnebre, Ambrosio alabó este gesto de arrepentimiento de su público pecado con gemidos y lágrimas, y que orando haya pedido perdón.

Terminaremos ahora con el problema africano, el cisma donatista, ya que conocemos la actitud de los distintos emperadores. Nos habíamos quedado en la proscripción del movimiento decretada por Constante. Esta situación duró hasta 362, cuando Juliano revivió el donatismo, que aunque oficialmente suprimido, persistía en la mayoría de sus seguidores, que no se manifestaban por miedo pero eran exhortados por sus obispos desde el exilio a perseverar. Mucha culpa tiene en esto la Iglesia, pues sus obispos carecieron del entusiasmo necesario para convencer, o quizás les faltó doctrina para instruir o se dejaron llevar por la fácil victoria, pensando que eso bastaba.

Cuando los obispos donatistas se dirigieron a Juliano para solicitarle el restablecimiento de su iglesia, este lo otorgó con facilidad a principios de 362 . Les concedió libertad de culto, retorno de los desterrados y restitución de todos los bienes muebles e inmuebles confiscados en 347. Como era de esperar, tal restablecimiento fue rápido, pero no pacífico. En algunos lugares los cismáticos quisieron borrar toda 
huella de la otra iglesia y destruyeron hasta sus olores: eucaristía, crisma, cálices y altares eran tirados por las calles o raspados hasta darles otra apariencia. Incluso algunos obispos encabezaron bandas violentas, aunque otros lo desaprobaron y trataron de impedir el uso de la fuerza. Los gobernadores de las provincias, interpretando la intención de Juliano, favorecían o toleraban la violencia. En 390, los donatistas llegaron al apogeo de su historia gracias a la labor de Parmeniano, sucesor de Donato en el exilio y que solo entonces pudo tomar posesión de su sede. Con celo, se dedicó a organizar su iglesia, por lo que se le considera un segundo fundador del donatismo. A su muerte, el cisma tenía casi tantos adeptos como sus rivales.

Entre 391 y 392 murieron los jefes de las dos iglesias y se cambiaron los papeles. En lugar del "bueno para nada" Genetlio, fue elegido Aurelio, un verdadero líder, que se convirtió en cabeza del cristianismo ortodoxo en África. El puesto de Parmeniano fue ocupado por un individuo conflictivo, Primiano. Además, por esas mismas fechas entró en escena Agustín, ordenado sacerdote en 391, después coadjutor de su obispo Valerio y en 395 obispo de Hippo Regius, Numidia. Fueron ellos, actuando siempre de acuerdo, los que inclinaron la balanza definitivamente para superar el cisma.

Por esos mismos años comenzó el turbio comportamiento de Gildón, jefe tribal de los cabiles en la Mauritania Cesariense, quien había llegado a ese puesto por su colaboración en la derrota de su hermano Firmo, en 372. La fidelidad de Gildón al Imperio comenzó a vacilar ante las medidas tomadas por Teodosio. Primero, le negó ayuda contra el usurpador Eugenio y después se aprovechó de la situación del Imperio a la muerte de Teodosio. Así, se rebeló en el otoño de 397 y se declaró súbdito del Imperio de Oriente. Al cabo, fue derrotado por su hermano Mascazel, adolorido porque había asesinado a su hijo. Gildón favoreció siempre a los donatistas y sus tropas tuvieron muchos miembros del cisma. De haber triunfado, otra habría sido la suerte del cristianismo en el África romana.

Ahora bien, esto sucedió porque el donatismo hacía causa común con los pobres y oprimidos, pues en las provincias donde tuvo mayor difusión sus habitantes eran agricultores: colonos o jornaleros, oprimidos 
por los patrones o por los funcionarios imperiales. La gran paradoja del África romana (considerada una tierra de promisión, el granero de Roma, de aquí que una espiga madura de trigo, signo de la fecundidad de la tierra, representaba a la diosa África) era que ayudaba a la alimentación de medio mundo, pero se alimentaba mal a sí misma, porque los recursos estaban mal distribuidos. Solo una minoría, no africana, disfrutaba la riqueza de su suelo, con el sudor de la gran masa de trabajadores nativos. Por haber sido conquistada en las guerras púnicas, era propiedad estatal por derecho, y al Estado pertenecían las ricas planicies, que habían sido repartidas entre la clase senatorial. Constantino, en su legislación para asegurar la manutención del Imperio y para evitar los continuos fraudes al fisco, había vinculado al campesino — colono, como se le llamaba - a su tierra, haciéndolo esclavo, en lo que se considera el inicio del siervo medieval. En 371, Valentiniano I ordenó: "Los colonos no tengan la libertad de abandonar los campos a los cuales los ligan su condición y su nacimiento. Si huyen y pasan a otro patrón sean reconducidos, encadenados y castigados". Aquí está la razón del problema, pues esta legislación, en lugar de robustecer la producción agrícola, fortaleció al patronato, ya que todos los que por malas cosechas no podían pagar los impuestos, los delincuentes comunes y hasta los criminales, huyeron a las fincas de los poderosos en busca de protección o más bien en busca de esfumarse, a cambio de lo cual ofrecían su trabajo y casi su libertad, pues difícilmente podían salirse de la finca sin correr el riesgo de que cualquiera los denunciara como fugitivos.

Estos asuntos de carácter socioeconómico se mezclaron con los religiosos. Por eso el donatismo alentaba cierta oposición política, incluso la rebelión, y evitaba todo trato con el Estado: Quid est imperator cum ecclesia, “Qué tiene que hacer el emperador en la iglesia?”, preguntaba Donato ante el tesón imperial por lograr la unidad.

\section{Los sucesores (395-430)}

A la muerte de Teodosio el 17 de enero de 395, lo sucedieron sus hijos, aunque conociendo su ineptitud, los había puesto bajo la tutela: a Arcadio, de Rufino en Oriente (395-408) y a Honorio, del vándalo Estilicón en 
Occidente (395-423). Teodosio no pensó dividir el imperio, como vulgarmente se piensa, sino que separó su administración como tantas veces se había hecho. Lo que ocurrió fue que por circunstancias posteriores, ya no fue posible la reunificación. Arcadio y Honorio se dejaron influir fácilmente y es larga la lista de quienes dispusieron del poder aconsejando a los soberanos. Lo mismo puede afirmarse de quienes los sucedieron: Teodosio II a Arcadio y Valentiniano III a Honorio (424-455). Se calcula que en este tiempo, principios del siglo V, los habitantes del imperio sumaban entre 40 y 50 millones, y se estima que los cristianos, dejando de lado si eran ortodoxos, bautizados o catecúmenos, eran la mitad de la población, o sea de 20 a 25 millones. Con menor número no se explicaría la medida de Teodosio al convertir el cristianismo en religión oficial del Estado.

Todos estos emperadores continuaron el repudio a la religión grecolatina. Así, Arcadio y Honorio promulgaron una constitución el 7 de agosto de 395 en la que prohibían la entrada a los templos paganos o de herejes, así como realizar sacrificios o actos de culto. Muchos lugares de culto sufrieron destrucción o graves daños, ya por parte de los funcionarios imperiales, ya por parte de los eclesiásticos, y se perdieron para siempre invaluables tesoros artísticos. Honorio se sintió obligado a dar una constitución, el 29 de enero de 399, en la que prohibió los sacrificios, pero mandó conservar los publicarum operum ornamenta, orden que repitió el 20 de agosto, para exigir la integridad de los edificios. En adelante, constituciones imperiales siguieron cerrando templos y prohibiendo sacrificios hasta mediados del siglo $\mathrm{V}$, por lo que podemos suponer que las órdenes no se ejecutaban de igual manera en todas las provincias.

Occidente sufrió una grave crisis administrativa, económica, social, militar al barbarizarse el ejército, y una demográfica por las inmigraciones de los pueblos germanos. Mientras estuvo al frente un ministro capaz, como era Estilicón, se pudo controlar la situación, pero al ser ajusticiado en 408, un gravísimo error político, comenzó a desmoronarse el Imperio. Alarico asaltó Roma el 24 de agosto de 410, lo que causó verdadero pánico en la Antigüedad, que tomó el hecho como un signo fehaciente del fin del mundo. En estas fechas Agustín escribía La ciudad 
de Dios, para refutar la tesis de los senadores romanos de que adorando el Imperio a los dioses era fuerte e invencible, pero que con el cambio de religión era presa de quien quisiera invadirlo. Efectivamente, muchos pueblos traspusieron la frontera norte del Imperio, pero no intentaban apoderarse de él ni mucho menos destruirlo, sino acogerse a las instituciones romanas. Desde tiempos de Augusto, pueblos enteros quedaron integrados al Imperio, incorporados predominantemente a las tropas, en las que algunos llegaron al mando supremo del ejército. Estas migraciones, mientras hubo un buen emperador o jefe pudieron ser controladas y aun absorbidas, pero al faltar una cabeza y ante la cantidad de pueblos que se cruzaban por hambre los límites del Imperio, se produjo una situación que terminó con la institución imperial en Occidente en 476. Se rompió un equilibrio inestable.

La parte oriental del Imperio tuvo ministros que fueron administradores capaces y manejaron mejor las invasiones de los bárbaros, ya pagando tributo para que realizaran sus fechorías en otro lado (en Occidente, con poca lealtad) ya apaciguándolos con prebendas, como por ejemplo al nombrar a Alarico, magister militum del Ilírico, con lo que lograron mantenerlo a distancia. Prueba de que no todo estaba perdido es la recopilación jurídica hecha bajo Teodosio II, el llamado Códice Teodosiano, publicado en 438, que reunió las constituciones imperiales de 312 a 437 y se convirtió en una de las bases de nuestro actual derecho.

Durante esta declinación constante del Imperio de Occidente, el emperador Honorio prestó su apoyo al cristianismo ortodoxo, en contra del donatismo, al que le aplicó las constituciones imperiales decretadas por su padre a los herejes, sin duda también con motivaciones políticas, por haber apoyado el levantamiento de Gildón, en el que fue ejecutado un obispo donatista muy amigo del derrotado.

Estas leyes solo se aplicaban esporádicamente, con las consiguientes respuestas violentas de los circumceliones contra fieles y clero de la otra iglesia. Honorio, cansado por las continuas quejas, el 5 de marzo de 405 quiso poner término a estas violencias con un nuevo Edictum de Unitate, con el que renovó los edictos dados por Constantino en 316 y por Constante en 347. Honorio equiparó a los donatistas con los herejes, 
los suprimió y ordenó la unidad so pena de graves castigos. La ley no fue aplicada de inmediato ni en todas partes. En algunos lugares desaparecieron las comunidades cismáticas, mientras que otras lograron sostenerse e incluso pasaron al ataque.

Era una época adecuada, ya que el donatismo estaba dividido, con un cisma en la sede de Cartago. Por otra parte, los cristianos sinceros del donatismo estaban cansados de tanta demagogia. Los obispos ortodoxos no perdieron el tiempo, sino que desarrollaron una vasta obra de propaganda y persuasión en una serie de concilios generales africanos anuales. Por otra parte, no se aceptaba tan fácilmente el empleo de la fuerza para apoyar la unidad, una cuestión que solo los hechos consumados después de 412 recibió cierta legitimación.

El momento culminante de este proceso de unidad fue la Conferencia de Cartago, que se había propuesto desde 401-402. Los obispos ortodoxos habían tenido la idea de celebrar una conferencia general entre los obispos de ambas iglesias, pero los donatistas la rechazaban siempre. Nuevamente, en el concilio cartaginense de 410 se repitió la propuesta y se enviaron delegados al emperador. Honorio aceptó la sugerencia y el 14 de octubre de 410 ordenó al tribuno Marcelino que se trasladara a Cartago para organizarla. Efectivamente, Marcelino preparó la conferencia en las termas Gargilianas de Cartago para el $1^{\circ} \mathrm{de}$ junio de 411. Cada iglesia debía elegir seis delegados, siete consejeros y cuatro notarios. Por la parte donatista fueron designados: Primiano, Petiliano de Constantina, la más alta personalidad del movimiento y gran orador, y Emérito de Cesarea, honesto y agradable. Los ortodoxos estuvieron representados por Aurelio, Agustín, Alipio de Tagaste y Posidio de Cálama. Asistieron 285 obispos donatistas y 286 ortodoxos. La conferencia representaba la máxima esperanza para lograr la unidad en la Iglesia africana.

La conferencia se verificó en tres sesiones, los días $1^{\circ}, 3$ y 8 de junio. Se leyeron multitud de documentos sobre el origen del cisma. En la tercera sesión, Agustín, orador de los ortodoxos, demostró que la Iglesia puede tener en su seno pecadores sin perder la santidad que le confiere el Espíritu Santo, y que la presencia de pecadores no es obstáculo para la comunión cristiana. Los donatistas no pudieron rechazar tales afirma- 
ciones, y como estas constituían el punto central del cisma, la noche del día 8 el presidente Marcelino declaró terminada la discusión con la victoria de los ortodoxos. El 26 del mismo mes se publicó un edicto por el que los donatistas debían regresar a la unidad, por ser los cismáticos, con pena de confiscación de bienes, cárcel y exilio para los desobedientes. El 30 de enero de 412 confirmó el emperador Honorio estas disposiciones y encargó su ejecución a los magistrados de las provincias y algunos funcionarios especiales.

Ahora bien, no pensemos que por arte de magia los donatistas obedecieron tranquilamente, ni siquiera en la polémica, pues por ejemplo en Agustín hay trazas de la presencia de los donatistas todavía en 420, y había grupos donatistas entre los bizantinos un siglo después. Lo más grave de esta turbación de la Iglesia africana fue que retardó o más bien impidió la cristianización de las tribus del interior del continente, así que cuando cayó el norte africano en poder del islam, en el siglo VII, se acabó la pujante Iglesia del África romana y el resto se transformó en una mina de esclavos.

Digamos ahora cuál es el pensamiento agustiniano sobre el Estado. Según Agustín, se debe obedecer a las autoridades temporales, aun si quienes ejercen el poder no son justos; por ello, reconocía la validez de cierta concordia, tranquillitas ordinis, con los Estados no cristianos, aunque no sea una verdadera paz, que es solo la celeste y eterna. Le parecía normal que la ciudad temporal aspirara a los bienes terrenos, aunque los bienes celestiales a los que aspira la ciudad celeste son mejores, porque el espíritu supera a la materia y lo eterno sobrepasa a lo que es pasajero.

Agustín distinguió los deberes de los gobernantes hacia Dios como hombres y otro tanto como reyes, es decir el aspecto privado y el público, aunque en cualquiera debían observar la justicia. Ahora bien, el emperador podía legislar en materia religiosa, pero de manera subordinada a la Iglesia.

No estaba de acuerdo Agustín con Cicerón en su definición de pueblo, porque los no cristianos no poseen la verdadera justicia, y por lo mismo no pueden formar un núcleo unido que sea fuente del derecho, 
aunque en la definición que propuso reconocía la existencia válida de los Estados no cristianos, porque aunque su justicia no sea verdadera, solo buscan los fines temporales. Un Estado sin justicia es una asociación para delinquir, por derecho, y de delincuentes, de hecho.

\section{Conclusiones}

1. La religión y el Estado al surgir el cristianismo formaban una amalgama perfecta, en la que el ciudadano, para serlo, debía venerar a los númenes estatales. No había ninguna separación entre lo religioso y lo político.

2. Al reconocer el Imperio romano al cristianismo como religión lícita, rompió con un principio sacro en su historia y aceptó del Estado una religión que no comulgaba con la estatal y que no pertenecía a ningún pueblo, sino a personas privadas.

3. Dado que el cristianismo se convirtió de improviso en la religión preferida por el emperador, siendo este Pontifex Maximus, y acudiendo a él los obispos como juez, fácilmente se convirtió en legislador de asuntos cristianos.

4. Es evidente que los emperadores cristianos cumplieron un papel de capital importancia tanto en su expansión dentro del imperio, como en la solución de los problemas teológicos o de disciplina interna que se ponían a su consideración. El apoyo estatal fue vital para solucionar dificultades en el campo teológico y también para alargar las controversias. Los emperadores convocaron todos los concilios ecuménicos de la época y sus resoluciones, mediante sendos edictos, se convirtieron en leyes para la ciudadanía.

5. Por lo anterior puede afirmarse que la libertad de religión proclamada por Constantino tuvo poca vigencia, seguramente porque el Estado imperial romano no estaba acostumbrado a dejar de ser eje de una religión que se estaba convirtiendo en predominante. Ya para fines de esta época, Teodosio II y Valentiniano III hablaban de crimen publicum de quien intentara desviar la doctrina cristiana. 
6. En síntesis, la amalgama perfecta entre religión y Estado al surgir el cristianismo, quedó en trance de volver a lo mismo, aunque no todos los líderes religiosos estaban de acuerdo en darle primacía al Estado. Poco más tarde, en Oriente, se fundió el cristianismo con el imperio y de ambos entes debía cuidar el emperador. En el código de Justiniano, al tratar los asuntos religiosos, se titula así el libro primero: De Summa Trinitate et fide catholica, ut et nemo de ea publice contendere audeat, "Sobre la Santísima Trinidad y la fe católica, para que nadie intente contender públicamente sobre ella". 
CITAM Derechos Reservados.

La reproducción total o parcial de este artículo se podrá hacer si el ITAM otorga la autorización previamente por escrito. 